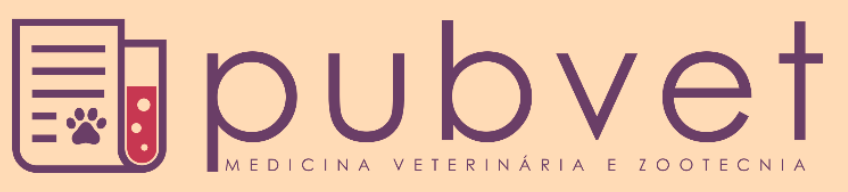

https://doi.org/10.31533/pubvet.v15n10a949.1-5

\title{
Hipoplasia de esmalte em cão: Relato de caso
}

\section{Marcos Vinicius Almeida Morais ${ }^{1} \bullet$, Mariana Faccini Pinheiro ${ }^{2} \bullet$, Rodrigo Antonio Martins ${ }^{3}$, Adriano de Oliveira Torres Carrasco ${ }^{3 *} \bullet$}

${ }^{I}$ Programa de Aprimoramento em Medicina Veterinária - Universidade Estadual do Centro - Oeste

${ }^{2}$ Universidade Estadual do Centro - Oeste

${ }^{3}$ Professor da Universidade Estadual do Centro - Oeste. Departamento de Medicina Veterinária - Guarapuava-PR, Brasil.

*Autor para correspondência: adriano.carrasco@gmail.com

Resumo. O esmalte dentário é o tecido mais mineralizado do organismo e possui função de revestimento e proteção do dente. É formado a partir de ameloblastos, estruturas muito sensíveis, que se sofrerem alguma injúria na sua formação, levam a defeitos no esmalte. A hipoplasia de esmalte é uma defeituosa formação da matriz orgânica do esmalte, levando a irregularidades na superfície e alteração na coloração. O diagnóstico é clínico e o tratamento é restauração, visando diminuir a sensibilidade dentária e cobrir dentina exposta. $\mathrm{O}$ objetivo foi relatar um caso de cão, fêmea, três anos de idade, com diagnóstico de hipoplasia de esmalte atendida na Clínica Escola de Veterinária Prof. Dr. Marcos Vinicius Tranquílim, da Universidade Estadual do Centro Oeste. Como tratamento, foi realizado limpeza periodontal e restauração dentária, visando uma melhor qualidade de vida para o paciente.

Palavras-chave: Dentina, placa bacteriana, procedimento odontológico, restauração

\section{Enamel hypoplasia in dog: Case report}

Abstract. The dental enamel is the most mineralized tissue from the body, providing coating and protection to the teeth. Its primary structural components are ameloblasts which, individually, are actually very sensitive structures. Whenever there is an injury to the amelogenesis we observe defects in the enamel. Enamel hypoplasia happens when there is a defective formation of its organic matrix, leading to irregularities on the enamel's surface and changes in its color. The diagnosis of this condition is based on clinical observation, and the treatment is restoration, which is aimed at decreasing dental sensitivity. The goal of this paper is to review a case of a female canine patient, diagnosed with enamel hypoplasia treated at Veterinary School Clinic Marcos Vinicius Tranquílim of the State University of Midwest. The case was conducted with a surgical periodontal treatment and a dental restoration, with the hopes of improving the quality of the patient's life.

Keywords: Dentin, bacterial plaque, dental procedure, restoration

\section{Hipoplasia del esmalte: Reporte del caso}

Resumen. El esmalte dental es el tejido más mineralizado del cuerpo, donde tiene la función de recubrir y proteger el diente. Está formado por ameloblastos, estructuras muy sensibles que, si sufren alguna lesión en su formación, conducen a defectos en el esmalte. La hipoplasia del esmalte es una formación defectuosa de la matriz orgánica del esmalte, que produce irregularidades en la superficie y cambios de color. El diagnóstico es clínico y el tratamiento es la restauración, con el objetivo de disminuir la sensibilidad dental y cubrir la dentina expuesta. El objetivo fue reportar un caso de una paciente canina, hembra, 
diagnosticada con hipoplasia del esmalte atendida en la Clínica Escuela Veterinaria Marcos Vinicius Tranquílim, Universidad Estatal del Centro Oeste. Como tratamiento, se realizaron la limpieza periodontal y la restauración dental, con el objetivo de mejorar la calidad de vida del paciente.

Palabras clave: Dentina, placa bacteriana, procedimiento dental, restauración

\section{Introdução}

O esmalte dentário é o tecido mais mineralizado do organismo e possui a função de revestimento e proteção do elemento dentário. Ele é formado a partir de estruturas chamadas ameloblastos, em três etapas: formação da matriz celular, mineralização e maturação, em que sofre a calcificação (Bevilacqua et al., 2010). Os ameloblastos no germe dentário em desenvolvimento são as células mais sensíveis do organismo no que se diz respeito a função metabólica. Qualquer fator, seja endógeno ou exógeno pode afetá-los, resultando em anomalias do esmalte (Santos et al., 2014).

A hipoplasia de esmalte pode ser definida como uma incompleta ou defeituosa formação da matriz orgânica do esmalte dentário em desenvolvimento, o que, por consequência, leva a deficiências e irregularidades na superfície do dente. Essas alterações podem aumentar a susceptibilidade para o acúmulo de placa bacteriana e aumento da sensibilidade dentária (Martinhão et al., 2015). Os fatores etiológicos podem ser divididos em duas grandes categorias, hereditária e ambiental. Esta última é a mais comum na prática clínica veterinária. Dependendo da causa, a condição pode afetar um ou apenas alguns dentes (forma localizada) ou toda a dentição (forma generalizada) (Boy et al., 2016).

Forma localizada é resultante de traumas na coroa em desenvolvimento ou infecção (abcessos periapicais) em dentes decíduos, que irão causar displasia no esmalte dos dentes adjacentes em formação. Já a forma generalizada advém de fatores sistêmicos, como deficiências nutricionais, distúrbios febris e hipocalcemia durante o período de formação do esmalte. Historicamente, a causa mais conhecida de picos febris e que levaram animais a apresentar essa afecção foi a cinomose, que hoje é facilmente prevenida com vacinação (Wiggs \& Lobprise, 1997).

Certos compostos e produtos químicos também podem levar à lesão do esmalte. A ingestão excessiva de flúor pode levar a manchas opacas, brancas e sem brilho no esmalte. Compostos de tetraciclina podem também causar alteração na coloração no tecido (Greenfield, 2012).

O controle genético da amelogênese é pouco conhecido, mas requer atividades de vários componentes exclusivos na formação do esmalte. Alguns tipos de heranças de displasia de esmalte foram descritos em humanos, porém a ocorrência de displasia hereditária em cães é desconhecida. Normalmente quando há distúrbio genético na formação do esmalte, tanto dentes decíduos quanto permanentes são afetados (Mannerfelt \& Lindgren, 2009).

O diagnóstico é feito por meio da avaliação clínica e avaliação detalhada das áreas escuras com um explorador, que revelará uma superfície danificada. Radiografias dentárias devem ser realizadas para descartar doença endodôntica e malformação radicular (Niemiec, 1995).

$\mathrm{O}$ esmalte normal funciona para selar o dente contra bactérias, protegê-lo e isolá-lo, fornecer resistência e criar uma superfície lisa, o que ajuda a impedir que a placa bacteriana se acumule na superfície do dente. Cães afetados com defeitos de esmalte, independentemente da causa, são propensos a abrasão e fratura de dentes, doença periodontal, sensibilidade dentária e possivelmente pulpite e morte pulpar. Como tratamento, a restauração dos dentes pode ser realizada para proteger a polpa do estresse térmico e mecânico e da infecção bacteriana, para diminuir a sensibilidade, a adesão da placa, a suscetibilidade à abrasão e fratura e melhorar a aparência cosmética (Bellows et al., 2019; $\underline{\text { Wiggs \& }}$ Lobprise, 1997).

O objetivo deste trabalho foi descrever um caso de hipoplasia de esmalte em um cão.

\section{Relato de caso}

Foi atendido na Clínica Escola de Veterinária Prof. Dr. Marcos Vinicius Tranquilím (CEVET), da UNICENTRO, Guarapuava -PR, um cão, sem raça definida, fêmea, com três anos de idade e 8,5 quilos. Animal vivia nas ruas, foi resgatada e adotada quando filhote. $\mathrm{Na}$ anamnese tutor relatou animal ter 
dificuldade em se alimentar, dentes amarelados e halitose. Sua alimentação era baseada em arroz com carne, e ração seca e úmida. $\mathrm{O}$ animal não possuía histórico de ter sido submetido a nenhum procedimento odontológico, assim como não havia uma rotina de higiene oral. Sangramentos e sialorreia também não eram relatados.

No exame físico, todos os parâmetros fisiológicos se encontraram dentro da normalidade para a espécie. No exame específico da cavidade oral, foi observado doença periodontal grau II, e observado em quase todos os elementos dentários, formação inadequada do esmalte, com bordas de irregulares e de coloração escura, o que indicava hipoplasia de esmalte (Figura 1).

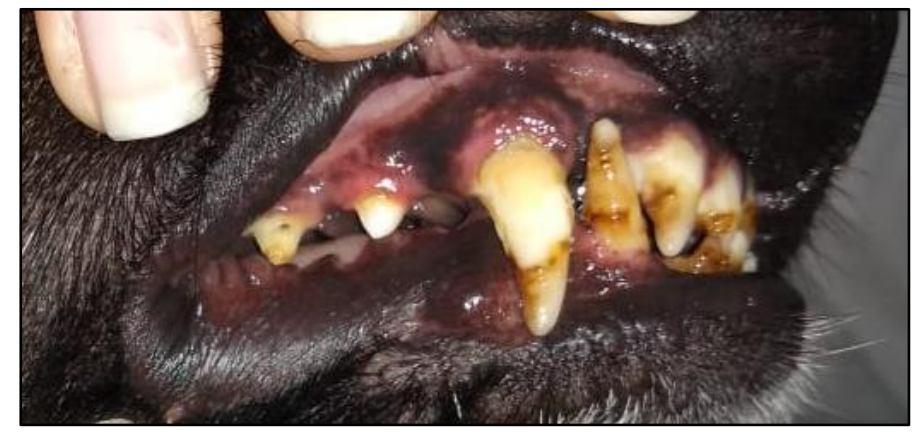

Figura 1. Lesões hipoplásicas em dentes incisivos, caninos e pré-molares.

O tutor foi orientado quanto a importância do tratamento periodontal e restauração dentária. Foram realizados os exames pré-operatórios (hemograma e perfil bioquímico) e agendado o procedimento odontológico. No dia do procedimento, animal foi submetido ao protocolo anestésico, que constituiu em medicação pré-anestésica com metadona $(0,5 \mathrm{mg} / \mathrm{kg})$, indução com propofol $(5 \mathrm{mg} / \mathrm{kg})$ e manutenção do plano anestésico com isofluorano. A partir do momento que animal já estava em plano anestésico adequado, foi possível observar detalhadamente a doença periodontal (Figura 2A). Então iniciou-se a limpeza, com uso de ultrassom odontológico e também a avaliação de todos os dentes, descartando alterações como mobilidades, exposições de furcas, bolsas periodontais e demais alterações (Figura 2B). Para o tratamento da hipoplasia de esmalte o primeiro passo foi o desgaste das áreas hipoplásicas, com brocas de pontas diamantadas (Figura 2C). Em seguida foi realizada a restauração dentária, iniciando pelo ataque ácido, com ácido fosfórico a 37,5\% por 20 segundos, após lavagem e secagem, a aplicação do agente de união (Magic Bond DE) e a fotopolimerização por 20 segundos. A resina composta microhibrida foi inserida em camadas na superfície dos dentes alterados. O tempo de fotopolimerização adotada foi de 40 segundos. Após todos os elementos dentários serem devidamente restaurados, foi realizado o polimento dentário com pasta profilática, para devolver superfície lisa aos dentes (Figura 2D).

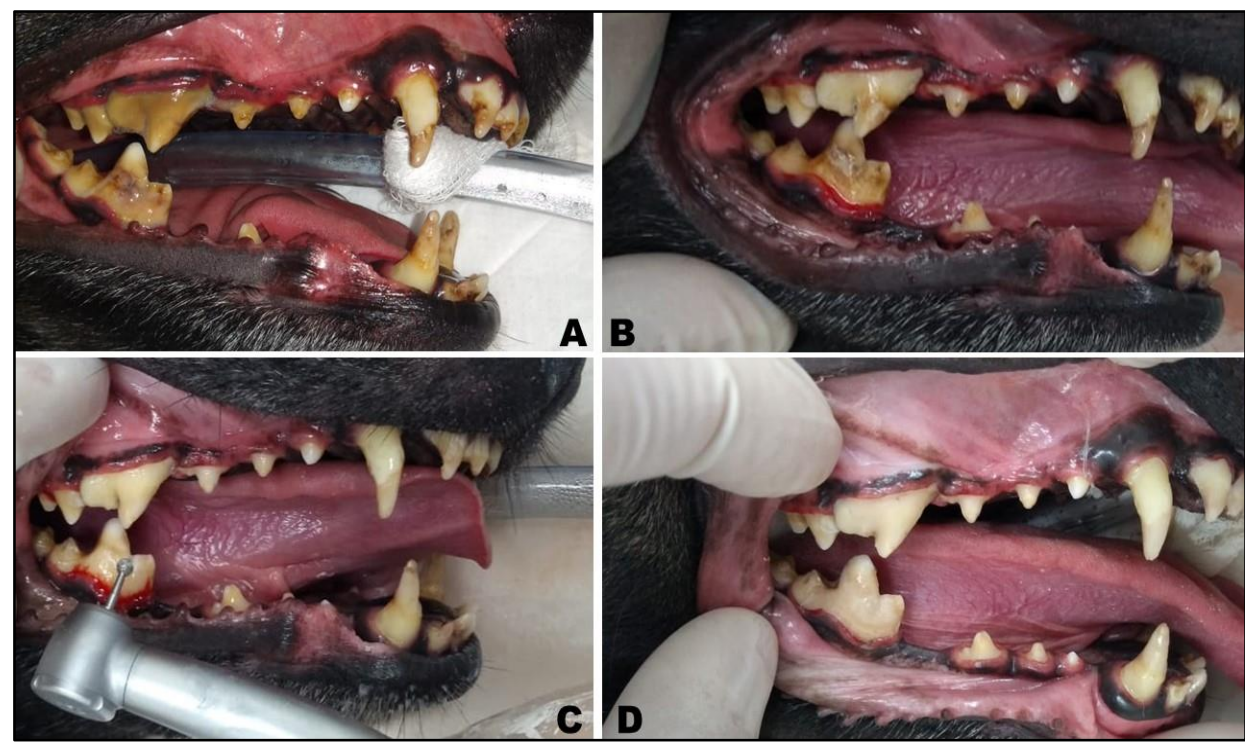

Figura 2. (A) Cavidade oral no início do procedimento, com presença de cálculos dentários. (B) Dentes após limpeza periodontal, evidenciando as áreas hipoplásicas. (C) Desgaste das áreas hipoplásicas com brocas diamantadas. (D) Elementos dentários restaurados. 
Para o pós-operatório, foi prescrito amoxicilina com clavulanato de potássio $20 \mathrm{mg} / \mathrm{kg}$ por vira oral a cada 12 horas durante sete dias, meloxicam $0,1 \mathrm{mg} / \mathrm{kg}$ por via oral a cada 24 horas durante três dias, limpeza oral diária com clorexidina $0,12 \%$ e em relação a alimentação, foi indicado apenas comida pastosa por cinco dias.

Após sete dias, o animal retornou à CEVET (Figura 3), e o tutor relatou que o animal estava mais ativo, comendo com menos dificuldade, mas ainda assim preferindo alimentos mais macios. Nesse dia foi orientado a manter escovação diária dos dentes, com uso da pasta dental enzimática, de uso veterinário.

\section{Discussão}

Segundo Southerden \& Gorrel (2007), a hipoplasia do esmalte (também chamada de displasia) pode ser definida como uma formação incompleta ou defeituosa da matriz orgânica do esmalte dos dentes. O resultado é esmalte defeituoso que pode ser causado por fatores locais, sistêmicos ou hereditários. No caso do relato, levando em consideração a falta do histórico do paciente, que foi resgatado, a causa é desconhecida.

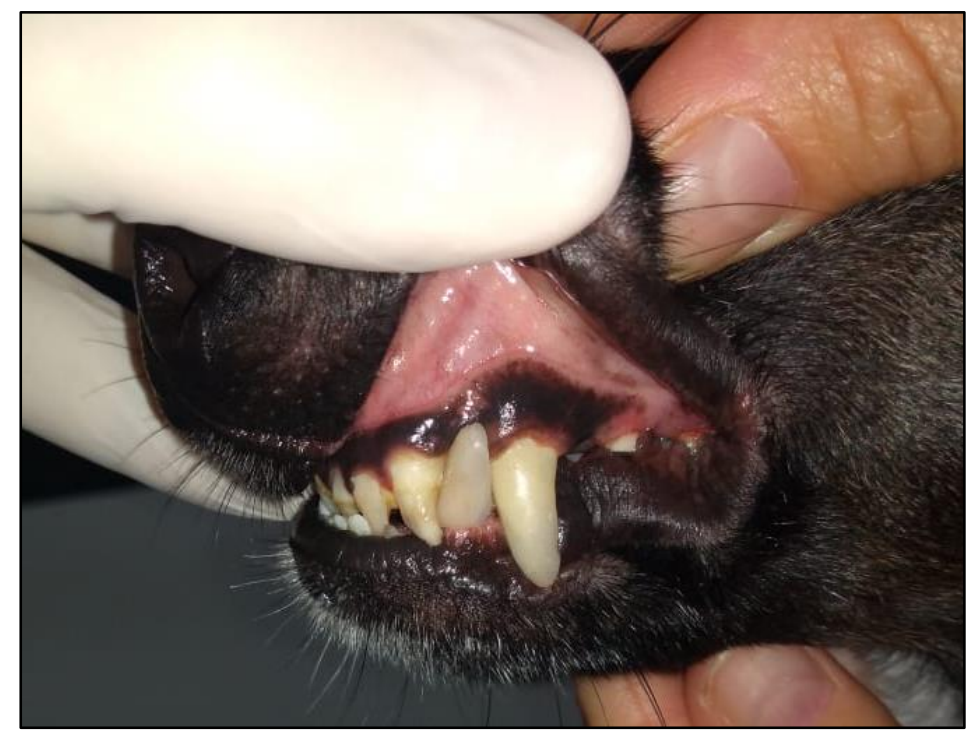

Figura 3. Imagem dos elementos dentários restaurados após sete dias do procedimento.

Em estudo de Bendo et al. (2007), uma criança de sete anos apresentando hipoplasia dentária foi encaminhada ao atendimento odontológico. Seu histórico incluía doença infecciosa com febre aos doze meses de idade, uma das causas que podem atuar na amelogênese. Na medicina veterinária, uma das causas que mais são reportadas decorrência dessa afecção é a cinomose. A infecção pelo vírus durante os estágios iniciais do desenvolvimento, antes da erupção da dentição permanente, pode infectar os brotos dentários e os ameloblastos, causando hipoplasia (Vijayanand et al., 2018). No presente caso, por se tratar de animal resgatado das ruas, pode ter sido acometido pelo vírus quando filhote e levado a problemas no desenvolvimento do esmalte.

Em estudos de Seow (1993), demostraram que pacientes com hipoplasia apresentam predisposição a gengivite pela superfície dentária não ser lisa e ser mais fácil adesão de placa bacteriana, além de uma alta sensibilidade dentária e relutância em realizar escovação. Tais observações corroboram com o quadro clínico descrito no presente relato, uma vez que o animal apresentava doença periodontal tanto pela superfície irregular das superfícies dos dentes, quanto pela ausência da escovação, além da dificuldade em se alimentar, devido a sensibilidade.

Campos et al. (2015) em seu estudo, relata a presença de lesão hipoplásica em apenas um dente de uma paciente humana, de onze anos e ainda explica que o caráter local, no caso por infecção é chamada de dente de Turner. $\mathrm{O}$ dente de Turner ocorre quando um dente decíduo apresenta uma infecção bacteriana que atinge o tecido periapical, afetando o dente permanente sucessor que ainda está em fase de formação da coroa. Não foi o caso do paciente relatado, pois a afecção ocorreu de forma generalizada. 
Segundo Niemiec (1995), o tratamento visa remover ou diminuir a sensibilidade, evitar infecção endodôntica e ocluir os defeitos, permitir uma superfície lisa ao dente e diminuir o acúmulo de placa. A maneira mais eficaz é realizando a restauração, que consiste na remoção da dentina doente até a aplicação da resina composta e sua fotopolimerização. Ainda indica que dentes pequenos, caso não seja possível a restauração, seja feita a exodontia. No presente relato, foi possível realizar a restauração de todos os elementos dentários hipoplásicos, sem nenhuma exodontia.

\section{Conclusão}

O diagnóstico correto e tratamento adequado é importante para pacientes com hipoplasia de esmalte. $\mathrm{O}$ esmalte tem como função proteger o dente e dar resistência, a restauração nesse caso foi realizada para melhor qualidade de vida para o animal, visto que esse tipo de tratamento diminui a sensibilidade dentária. Como é um procedimento que precisa de acompanhamento e a restauração normalmente precisa ser refeita, é importante que o paciente seja reavaliado periodicamente por um especialista em odontologia veterinária.

\section{Referências bibliográficas}

Bellows, J., Berg, M. L., Dennis, S., Harvey, R., Lobprise, H. B., Snyder, C. J., Stone, A. E. S., \& Van de Wetering, A. G. (2019). 2019 AAHA dental care guidelines for dogs and cats. Journal of the American Animal Hospital Association, 55(2), 49-69. https://doi.org/10.5326/JAAHA-MS-6933.

Bendo, C. B., Scarpelli, A. C., Novaes Júnior, J. B., Vale, M. P. P., Paiva, S. M. de, \& Pordeus, I. A. (2007). Hipoplasia de esmalte em incisivos permanentes: um acompanhamento de 6 meses. Revista Gaúcha de Odontologia, 55(1), 107-112.

Bevilacqua, F. M., Sacramento, T., \& Felício, C. M. (2010). Amelogênese imperfeita, hipoplasia de esmalte e fluorose dental-revisão da literatura. Revista Brasileira Multidisciplinar, 13(2), 136-148.

Boy, S., Crossley, D., \& Steenkamp, G. (2016). Developmental structural tooth defects in dogsexperience from veterinary dental referral practice and review of the literature. Frontiers in Veterinary Science, 3, 9.

Campos, P. H., Guaré, R. O., \& Diniz, M. B. (2015). Dente hipoplásico de Turner: relato de casos clínicos. Revista Da Faculdade de Odontologia-UPF, 20(1), 88-92.

Greenfield, B. A. (2012). Enamel defect restoration of the left mandibular first molar tooth. Journal of Veterinary Dentistry, 29(1), 36-43. https://doi.org/10.1177/089875641202900106.

Mannerfelt, T., \& Lindgren, I. (2009). Enamel defects in standard poodle dogs in Sweden. Journal of Veterinary Dentistry, 26(4), 213-215. https://doi.org/10.1177/089875640902600407.

Martinhão, L. D., Guadagnin, V., Mantovani, M., \& Fracalossi, C. (2015). Hipoplasia de esmalte: uma abordagem clínica conservadora. Revista Uningá, 24(1), 27-32.

Niemiec, B. (1995). Small animal dental, oral and maxillofacial disease: A colour handbook. Mason Londres. https://doi.org/10.1201/b18171.

Santos, C. T., Picini, C., Czlusniak, G. D., \& Alves, F. B. T. (2014). Anomalias do esmalte dentáriorevisão de literatura. Archives of Health Investigation, 3(4), 74-81.

Seow, W. K. (1993). Clinical diagnosis and management strategies of amelogenesis imperfectavariants. Pediatric Dentistry, 15(6), 384-393.

Southerden, P., \& Gorrel, C. (2007). Treatment of a case of refractory feline chronic gingivostomatitis with feline recombinant interferon omega. Journal of Small Animal Practice, 48(2), 104-106.

Vijayanand, V., Simon, M. S., Methai, A., Kavitha, S., \& Sathiamoorthy, T. (2018). Enamel hypoplasia in canine distemper recovered pup: A case report. The Indian Journal of Veterinary Sciences \& Biotechnology, 14(02), 69-70. https://doi.org/10.21887/ijvsbt.14.2.17.

Wiggs, R. B., \& Lobprise, H. B. (1997). Veterinary Dentistry: principles and practice. Lippincott-Raven Publishers.

Histórico do artigo:

Recebido: 1 de maio de 2021

Aprovado: 5 de junho de 2021
Licenciamento: Este artigo é publicado na modalidade Acesso Aberto sob a licença Creative Commons Atribuição 4.0 (CC-BY 4.0), a qual permite uso irrestrito, distribuição, reprodução em qualquer meio, desde que o autor e a fonte sejam devidamente creditados. 